\title{
Stylistic Study of Thematic Structure and Thematic Features in Ama A. Aidoo's "Comparisons or Who Said a Bird Cannot Father a Crab?"
}

\author{
Ayodele Adebayo Allagbé ${ }^{1^{*}}$, Yémalo Célèstin Amoussou ${ }^{2}$, Dorothée Tchada ${ }^{3}$ \\ ${ }^{1}$ Département d'Anglais, Faculté des Lettres et Sciences Humaines (FLSH), Université de Zinder (UZ), \\ République du Niger. \\ 2Département d'Anglais, Faculté des Lettres, Langues, Arts et Communication (FLLAC), Université d'Abomey- \\ Calavi (UAC) République du Benin. \\ ${ }^{3}$ Ecole Pluridisciplinaire (EDP), Université d'Abomey-Calavi (UAC), République du Benin.
}

*Corresponding Authors: Ayodele Adebayo Allagbé, Département d'Anglais, Faculté des Lettres et Sciences Humaines (FLSH), Université de Zinder (UZ), République du Niger.

\begin{abstract}
This paper seeks to examine the Thematic structure and Thematic features in Ama Ata Aidoo's short story entitled "Comparison or Who Said a Bird Cannot Father a Crab?" in order to take stockof how they realize the writer's literary style. It draws its theoretical construct-THEME - from Systemic Functional Linguistics (SFL henceforth) (Halliday and Hasan, 1976, Halliday and Matthiessen, 2004, Eggins 1994/2004, Bloor and Bloor, 2004, etc.). The study begins with a lexicogrammatical clause-by-clause description of the story with a view to pinpointing the salient linguistic properties the writer employs to encode Textual meaning therein. The findings reveal the use of so many clause simplexes packaged into clause-complexes but predominantly rife with Topical Themes in a usual/normal/expected position/slot. They also exude the deployment of a considerable rate of marked Themes and marked dependent Themes. All these, de facto, denote a combination of the features of both spoken and written language in the story.
\end{abstract}

Keywords: Literarystyle Thematic structure, thematic features, theme, textual meaning.

\section{INTRODUCTION}

Research has established that a clause's Thematic potential is replete with many alternatives in terms of the positioning or packaging of its constituents for different or particular purposes. In fact, creative users of language are aware of the striking variation/deviation they (can) operate invariably from the way they manipulate the structure of language. For instance, a circumstance of location (otherwise known as adverb of place) can be placed at/in the frontal position, medial position or final position of/in a clause, as in: a. In Cotonou, there are many buildings. b. There are in Cotonou many buildings. c. There are many buildings in Cotonou. While it is obvious that these three samples exhibit the same clause constituents, they do not actually mean the same thing from a Thematic perspective. It follows from this to note that a choice of one of the three alternatives (a., b. and $\mathbf{c}$.), de facto, represents a style-marker or encodes an idiosyncratic style.

This paper seeks, as it were, to examine the Thematic structure and Thematic features in Ama Ata Aidoo's short story entitled "Comparison or Who Said a Bird Cannot Father a Crab?" in order to take stock of how they realize the writer's literary style. Leech and Short (1981:9) define style as "the way in which language is used in a given context, by a given person, for a given purpose, and so on". But by style, we mean all the foregrounded linguistic features which obviously characterize the writer's literary language, and, by implication, her individuality. To study a writer's style, one needs to make recourse to stylistics. By definition, stylistics is the linguistic study of style (Leech and Short, 1981). Talking about the importance of and the dialectical link between style and stylistics, Leech and Short (1981:13) observe the following: "We normally study style because we want to explain something and in general, literary stylistics has, implicitly or explicitly, the goal of explaining the relation between language and artistic function". This stylistic study is actually informed by a linguistic theory called Systemic Functional Linguistics (SFL henceforth) (Halliday and Hasan, 1976, Halliday and Matthiessen, 2004, Eggins 1994/2004, Bloor and Bloor, 2004, etc.), mainly THEME. 


\section{THEORETICAL FrameWORK: THEME AND THEMATIC STRUCTURE}

Systemic Functional Linguistics (SFL, henceforth) is a functional-semantic approach to language analysis (Eggins, 1994/2004). This approach advances three types of grammar: TRANSITIVITY, MOOD and THEME. Of these three types of grammar, THEME is considered by systemic scholars (Halliday and Hasan, 1976, Halliday and Matthiessen, 2004, Eggins 1994/2004, Bloor and Bloor, 2004 , etc.) as the means by which texts generally negotiate Textual meaning/metafunction. In this guise, Eggins (1994:273) argues that THEME is "The level of organization of the clause which enables the clause to be packaged in ways which make it effective given its purpose and its context". It ensues from the foregoing that THEME (otherwise known as the grammar of Textual meaning) has the potential of creating meaning in text in that it helps to structure clause constituents in consonance with the speaker's/writer's/narrator's purpose as well as with the context of use. In other words, THEME has the distinctive feature of creating texture in text.

While Halliday (2002:44-45) contends that generic structure, textual structure (thematic and informational) and cohesion are three factors that differentiate 'text' from 'non-text', Halliday and Hasan (1976) aver that texture is what distinguishes text from non-text. Actually, texture is generated in the clause via "the total theme-rheme structure" (Halliday, 1971:331). While Theme refers to the starting point for the message: it is what the clause is going to be about, Rheme points to the part of the clause in which the Theme is developed (Eggins, 2004:209-300). There are three basic types of Theme, viz. Topical (or Experiential), Interpersonal and Textual. A Topical or Experiential Theme is the starting point of the clause to which a Transitivity function (participant, process or circumstance) is assigned. An Interpersonal Theme is the point of departure of the clause to which a Mood label (subject, finite, vocative, etc.) is given. Textual Theme refers to clause elements which occur in Thematic position which can neither be assigned a Mood label nor a Transitivity label. They play an important role of cohesive work by relating the clause to its context. There are two types of textual elements, namely: continuity adjuncts (e.g. oh, yes/yea/yep, no/nope, well, etc.) and conjunctive adjuncts (e.g. and, then, but, yet, however, etc.).

It must also be noted that, in addition to the three basic types of 'Theme', there exist other specific types: marked and unmarked Themes. A Theme that conflates with any other constituent from the Mood system is called a marked Theme. Theme markedness in this sense accounts for the obvious relationship between the Mood and Theme structures of the clause; it accounts for how the functional roles assigned to constituents in a Theme analysis conflate with the functional roles assigned to constituents in the Mood structure. One strategy of creating a marked Theme is to move a Circumstantial element to Thematic position, as in: On Tuesday, Paul visited the garden. An unmarked Theme is a Theme that conflates with the Mood structure constituent that typically occurs in first position in clauses of that Mood class (Eggins, 1994:296). In other words, an unmarked Theme is the Theme that is playing the following roles: Subject (in a declarative clause), Finite (in an interrogative clause), Predicator (in an imperative) and WH-element (in a wh-interrogative). E.g.: She rubbed her crusty eyes. The other two types of Theme (interpersonal and textual) can be marked too (see Amoussou, 2016:217 for more details).

There is also what is known as a 'multiple Theme'. Eggins (2004:307) actually holds that when several textual Themes or/and interpersonal Themes occur before the obligatory topical Theme, this combination is called a 'multipleTheme'. One can also distinguish between 'a textual Theme' and 'a structural one'. While the former is generally a coordinating conjunction (and, then, but, yet, however, etc.), a subordinating conjunction (when, before, after, how, etc.) or a continuity adjunct (oh, yes/yea, no, well, etc.), the latter has to do with the use of relative pronouns such as 'who, which, that, etc.'(Amoussou, 2016:217).

\section{Methodology}

This stylistic analysis of the Thematic structure and Thematic features in Aidoo's short story entails the segmenting of the text into clauses. Each clause is numbered and each Theme-type is identified, underlined and quantified. And the classification of the Theme-types is done following Amoussou (2016:217). He proposes a Theme classification with six classes (a, b, c, d, e \& f) which this study slightly builds on: 
Stylistic Study of Thematic Structure and Thematic Features in Ama A. Aidoo's "Comparisons or Who Said a Bird Cannot Father a Crab?"

Table1: Theme Classification

\begin{tabular}{|l|l|}
\hline Theme classes & Structure/Composition of the Theme \\
\hline (a) & 'only a transitivity-label item or topical Theme' \\
\hline (b) & 'textual element+ topical theme' \\
\hline (c) & $\begin{array}{l}\text { 'Interpersonal element+ topical theme' } \\
\text { element + topical theme' }\end{array}$ \\
\hline (d) & 'structural element' \\
\hline (e) & 'textual element+ structural element/'structural element+ Topical theme' \\
\hline (f) & 'minor clause' \\
\hline (g)
\end{tabular}

\section{Identification of Theme-types and Thematic Structure in the Short Story}

1i. OF COURSE, we ${ }^{(\mathbf{c})}$ 've heard 1ii. $\underline{\mathbf{i t}}^{(\mathbf{a})}$ said of identical twins. 2i. Butnot only WERE these $\underline{\text { two }}^{(\mathbf{d )})}$ nothing of the kind, 2ii. they ${ }^{(\mathbf{a})}$ were not even remotely kin. 3. And HADN'T we ${ }^{(\mathbf{d})}$ been told of the mysteries of the generation gap? 4. Who ${ }^{(\text {a) }}$ were they? 5. One of them ${ }^{(a)}$ was my father. 6.

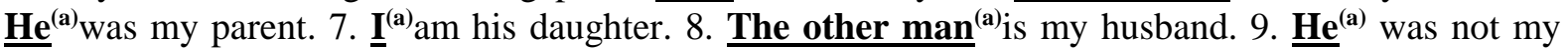
father's son. 10i. $\underline{\text { So how }}^{(\mathbf{b})}$ could they resemble one another so much, 10ii. at leastin those areas ${ }^{(\mathbf{b})}$ I consider essential to our very being, like our sense of self? 11i. Here ${ }^{(a)}$ are the numbers that really count ... ah, 11ii. but first, $\mathbf{i t}^{(\mathbf{b})}$ 's the news about a friend's house 11iii. that $^{(\mathbf{e})}$ got flooded in the night's storm, 11iv. all essential papers and other precious possessions ${ }^{(\mathbf{a})}$ (got) ruined. 12. OF COURSE, it ${ }^{(\mathrm{c})}$ was new. 13. Butthe developers, [lincluding those who walk // and work in the $\underline{\text { name of the statell }}^{(\mathbf{b})}$, could not be bothered to use engineers. 14i. She ${ }^{(\mathbf{a})}$ needs someone 14ii. to ${\underline{\text { contact }^{(\mathbf{a})}} \text { her lawyers, insurance brokers ... 15i. Thenthere }}^{(\mathbf{b})}$ are all those accidents here 15ii. $\underline{\text { where }}^{(\mathbf{a})}$ half of the drivers on the road bought their driving licences 15iii. andthe other half ${ }^{(\mathbf{b})}$ are completely blind, $15 \mathrm{iv}$. but (they) $^{(\mathbf{b})}$ will not go to have their eyes checked, $15 \mathrm{v}$. or (they) $^{(\mathbf{b})}$ cannot afford to, 15vi. sothe corrective glasses ${ }^{(\mathbf{b})}$ are out of the question, no lies or exaggerations ... $16 \mathrm{i}$. $\underline{W e}^{(a)}$ get cancers from the water from ancient leaded pipes 16ii. thatwe ${ }^{(\mathbf{b})}$ needs must drink to avoid those dangerous germs and bacteria. 17. The foods [[that nourish today] (a) $^{(2)}$ kill tomorrow ... 18. $\underline{\text { Now }}^{(\text {a) }}$, I pick up my bag. 19. $\underline{\mathbf{I}}^{(\mathrm{a})}$ walk to the car. 20. $\underline{\mathbf{I}}^{(\mathrm{a})}$ am close to tears. 21 . The third time this morning $^{(\text {a) }}$ (I am close to tears). 22. The only reason [لI'm not screaming] ${ }^{(a)}$ is [[because I don't want the children // to see // or hear me in that state]]. 23i. No more than $\mathbf{I}^{(\mathbf{b})}$ would allow them 23ii. to stuff $^{(\text {a) }}$ their heads with the contents of early morning global news. 24. (IS it $\left.{ }^{(\mathbf{c})}\right)$ Right?25i. FACTS ${ }^{(\mathbf{a})}$ THAT SHOULD NOT CONFIDE, 25ii. $\underline{B U T}$ (THEY) $^{(\mathbf{b})}$ CONFUSE ALL THE SAME. $26 \mathrm{i} . \underline{A s \mathbf{I}^{(\mathbf{b})}}$ said, 26ii. he ${ }^{(\text {a) }}$ was my father. 27. So OF COURSE I ${ }^{(\mathbf{d})}$ look like him. 28i. Although some people ${ }^{(\mathbf{b})}$ tell me 28ii. that $\mathbf{I}^{(\mathrm{b})}$ am so much more like my mother, 28iii. 'it ${ }^{(\mathrm{a})}$ 's uncanny!' 29. That ${ }^{(\mathrm{a})}$ 's another thing. 30. This business of whom a child ${ }^{(\mathbf{a})}$ resembles. 31 . $\underline{\mathbf{t}}^{(\mathbf{a})}$ depends on [[who is doing the seeing, $/ /$ and perhaps what they are quite probably, quite unconsciously, looking for]]. 32. No? ? $^{(\mathbf{c})} 33 \mathrm{i}$. As far as $I^{(b)}$ can remember, 33ii. all my father's relatives ${ }^{(a)}$ always swore [[that I resemble my father so much // that if I had not been female, // I could have been mistaken for him anytime.]] 34i. It $^{(\mathbf{a})}$ 's the same tale 34ii. my mother's people and her friends ${ }^{(a)}$ told. 35 . With a little more conviction ${ }^{(\text {a) }}$ of course, since with them, there were never ifs or buts. 36. The question ${ }^{(a)}$ is: [[if I look like both my parents, // and therefore there is no question // that my father's blood flows through my veins and all that, // then how could he and I have differed so much in all the other ways // that mattered? ... to me anyway?]] 37. The wedding ${ }^{(\mathbf{a})}$ had been very expensive, no surprise there. 38 . And (they ${ }^{(\mathbf{b})}$ had been very) exhausting: physically, mentally, and physically. 39i. Butthat ${ }^{(\mathbf{b}) \text { 's }}$ what $39 \mathrm{ii}$. weddings $^{(\mathbf{a})}$ are supposed to do to you, no? 40. [What the two of us had decided, rather wisely]l ${ }^{(\mathbf{a})}$, was [[that we would go all the way, dze kaw ato kaw do, // and give ourselves a decent honeymoon, // from which we would return to face the debts together]]. 41i. $\underline{\mathbf{W h i c h}}^{(\mathbf{e})}$ is exactly 41ii. $\underline{\text { what }}^{(\mathbf{a})}$ happened. 42. $\underline{\mathbf{I}}^{(\mathbf{a})}$ don't remember the details of my days the first few years of marriage. $43 . \underline{\mathbf{I}}^{(\mathbf{a})}$ can only talk about these days. 44. (I mean) Today ${ }^{(\mathbf{a})}$. 45. (I mean) Now ${ }^{(\mathbf{a})}$. 46. $\underline{\mathbf{W e}}^{(\mathrm{a})}$ both work. 47i. $\underline{\mathbf{M e}}^{(\mathrm{a})}$ (work as) a bank clerk, 47ii. $\underline{\text { andhe }}^{(\mathbf{b})}$ (works as) a pharmacist with the Ministry of Health, 47iii. which $^{(\mathbf{e})}$ means [[that he works in the dispensary in the central hospital here.]] $48 . \underline{\mathbf{W e}}^{(\mathbf{a})}$ are both paid very badly. 49.

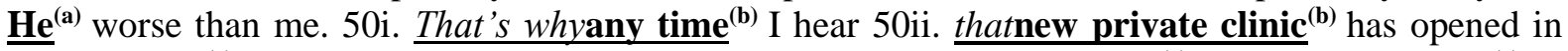
town, 50iii. $\underline{\mathbf{I}}^{(\mathrm{a})}$ literally run home, or more often to the hospital, 50iv. $\underline{\text { to tell }}^{(\mathbf{a})}$ him about it. 51i. ' $\underline{\mathbf{I}^{(\mathbf{a})} \text { 'm }}$ 
biding my time,' 51ii. he ${ }^{(\mathbf{a}) '} 11$ say mysteriously. 52. $\underline{\text { Which }}^{(\mathbf{e})}$ in normal language means [[that he's waiting // until the government sends him a letter // informing him // that he's been transferred from

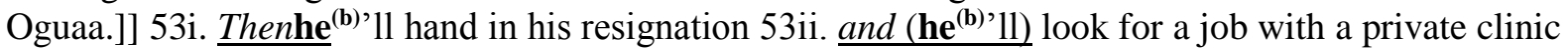
in this town. 54. DOES it ${ }^{(\mathrm{c})}$ make sense? 55. What ${ }^{(\mathbf{a})}$ I mean is, [[if something bothers him about his government job, // and something obviously does ... // it's the pay.]] 56. (The pay ${ }^{(a)}$ is) Humiliating. 57. $\underline{\text { Sowhy }}^{(\mathbf{b})}$ doesn't he just quit? 58. $\underline{\mathbf{I}}^{(\mathbf{a})}$ don't know ... 59i. $\underline{\text { Andthis }}^{(\mathbf{b})}$ isn't the only area 59ii. where $^{(\text {a) }}$ I don't understand my husband. 60 . BACK THEN ${ }^{(a)}$, I can see him, after his early morning rituals, in his khaki farm clothes. 61. Ah, those khaki shorts and the shirt ${ }^{(\mathbf{b})}$ that he must have worn to the farm over a thirty-year period. $62 \mathrm{i}$. When $\mathbf{I}^{(\mathbf{b})}$ emerged from babyhood to adulthood, $62 \mathrm{ii}$. $\underline{\text { those clothes }}^{(\text {a) }}$ already looked worn and stained. 63. (They ${ }^{(a)}$ already looked worn and stained) Not nastily, as with splashes of grease and drops of food. 64. But (they ${ }^{(\mathbf{a})}$ looked) naturally, randomly dyed with the juices and resins of the woods and the farms. 65 . $\underline{\text { All }}^{(\mathbf{a})}$ (he got) in his day's work. 66. (He ${ }^{(\mathbf{a})}$ got) Big patches of stains. 67. (Which ${ }^{(\mathbf{e})}$ looked) Like tie-and-dye. 68. Except that the process ${ }^{(\mathbf{b})}$ had been more organic. 69. MAYBE there $^{(\mathfrak{c})}$ was more than a pair, perhaps two pairs of them, at least. 70i. But when $\mathbf{I}^{(\mathbf{b})}$ was a kid, 70ii. $\underline{\mathbf{I}}^{(\mathbf{a})}$ saw, 70iii. $\underline{\text { or }}\left(\underline{\mathbf{I}}^{(\mathbf{b})}\right)$ thought $70 \mathrm{iv} . \underline{\mathbf{I}}^{(\mathbf{a})}$ saw, only one, the frayed edges of the entire ensemble also seeming a permanent feature. 71. Banana Republic ${ }^{(\mathbf{g})}$. 72. Stylishly elegant on male and female manikins in New York, London and Paris ${ }^{(\mathbf{g})}$. 73. The price? ${ }^{(\mathrm{g})} 74$. Fat enough ${ }^{(\mathrm{g})}$. 75i. And ${ }^{(\mathbf{b})}$ thought, 75ii. 'How uncanny ${ }^{(\mathbf{a})}$ the resemblance! 76. DID their researchers ${ }^{(\mathbf{c})}$ know him, my father?' 77i. Once upon a time ${ }^{(\mathrm{a})}$, there was a bright, eager young woman 77ii. who $^{(\mathrm{e})}$ had been a student volunteer to one of those tropical paradises 77iii. where $^{(\text {a) }}$ both the condemned and the saved live, 77iv. who ${ }^{(\mathrm{e})}$, on her return, in a discussion with a friend ... 77v. that friend ${ }^{(\mathrm{a})}$ being an upwardly mobile young man 77vi. who ${ }^{(\mathrm{e})}$ nodded to know [[where the most exotic and environmentally friendly dyes could be found for his office, a rather well-known design house for outfitting the very chic denizens of the modern workplace, with equally chic, very contemporary, elegant, but affordable rags

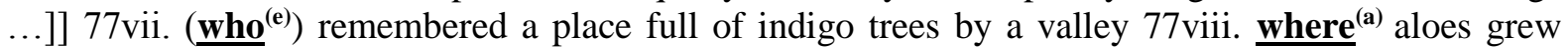
wild and lush on the edge of the rainforest. 78i. This information ${ }^{(a)}$, [[sourced and acted on]], had yielded a mighty promotion and a massive salary for one so young, 78ii. and PERHAPS the young man on his way to the rainforest for the said indigo ${ }^{(\mathbf{d})}$ had seen my father- or maybe someone else's father- [[wearing, [yes, you've got it], the old, faded, patched and frayed pair of khakis]], 78iii. and (the young man $^{(\mathbf{b})}$ ) being clever 78iv. and (the young $\operatorname{man}^{(\mathbf{b})}$ ) wanting to amaze his company with his gift of innovation and flair, 78v. (the young $\mathbf{m a n}^{(\mathbf{a})}$ ) had immediately, and hurriedly, sketched the style, later properly made up. 79i. 'Oh, ISN'T he ${ }^{(\mathrm{d})}$ cool?' ... 79ii. his genius ${ }^{(\mathrm{a})}$ received instant recognition, 79iii. andthe rest $^{(\mathbf{b})}$, [[as they say]], is history. 80i. Sothere ${ }^{(\mathbf{b})}$ was my father, in his farm fatigues, 80ii. quite unconscious ${ }^{(\mathbf{a})}$ (he was) 80iii. thathe ${ }^{(\mathbf{b})}$ was in the vanguard of high fashion, 80iv. ${\left(\underline{\mathbf{h e}}^{\text {(a) }} \text { was) ready 80v. and (he }\right.}^{(\mathbf{b})}$ was) raising to go 80vi. and (he ${ }^{(\mathbf{b})}$ was raising to) start working at cockcrow. 81. TODA $\underline{\mathbf{Y}}^{(\mathbf{a})}$. 82i. $\underline{\mathbf{I}}^{(\mathbf{a})}$ wake up at 5 a.m., 82ii. $\left(\underline{\mathbf{I}}^{(\mathbf{a})}\right)$ go to the bathroom, then to the children's room 82iii. to wake ${ }^{(\mathbf{a})}$ them up, 82iv. $\underline{\text { which }}^{(\mathbf{e})}$ is already a job and a half, $82 \mathrm{v}$. $\left(\underline{\mathbf{I}}^{(\mathbf{a})}\right)$ prod them towards the bathroom, 82vi. Abiw ${ }^{(a)}$ branching off to the conveniently separate loo 82vii. $\underline{\text { while }}^{\mathbf{I}^{(\mathbf{b})}}$ drag Nancy all the way to the hand basin 82viii. where ${ }^{(\mathbf{a})}$ I have to hover around to make sure 82ix. she ${ }^{(a)}$ actually brushes her teeth. 83 . Five years old ${ }^{(\text {a) }} \ldots$ not that her brother is better at eight ... 84i. Andnow $^{(\mathbf{b})}$ he is out of the bathroom, 84ii. soMiss Bladderrock ${ }^{(\mathbf{b})}$ (is out of the bathroom), 84iii. yes, she $^{(\mathbf{b})}$ is one of those, 84iv. andwhat a blessing ${ }^{(\mathbf{b})}$ such are to mothers $-84 \mathrm{v}$. $\underline{\text { touch }}^{(\mathbf{a})}$ wood, 84vi.

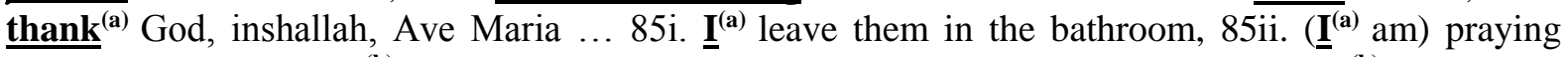
silently 85iii. thatthey ${ }^{(\mathbf{b})}$ 'll get on with their baths, 85 iv. instead of (the children ${ }^{(\mathbf{b})}$ ) ${ }^{\text {starting an }}$ argument so early in the morning about nothing at all. 86. If the tap ${ }^{(\mathbf{b})}$ is running. $87 \mathrm{i}$. If it $^{(\mathbf{b})}$ isn't, 87ii. then $\mathbf{I}^{(\mathbf{b})}$ rush to the tanks 87iii. $\underline{\text { to }}^{\text {fetch }}{ }^{(\mathbf{a})}$ Nancy half a bucketful, 87iv. and INVARIABLY $\left(\mathbf{I}^{(\mathbf{d})}\right)$ collide with Abiw $87 \mathrm{v} . \underline{a s h e}^{(\mathbf{b})}$ is running to turn on the TV. 88. None of my very patient and careful entreaties $^{(\text {a) }}$ have been effective. 89 . Neither of the two stations ${ }^{(\mathbf{a})}$ here runs programmes for children in the morning. 90i. And WOULD you ${ }^{(\mathbf{d})}$ want your children 90ii. to swallow ${ }^{(\mathbf{a})}$ the early morning load of news about the world's murders, mayhem and general mess with their cocoa? $91 \mathrm{i}$. $\underline{\mathbf{I}}^{\text {(a) }}$ dash back to the bathroom 91ii. to help ${ }^{(\mathbf{a})}$ Nancy with her bath. 92i. But beforeshe ${ }^{(\mathbf{b}}$ is through ${ }^{\text {) }},{ }^{2}$ 2ii. $\underline{\mathbf{I}}^{(\mathbf{a})}$ have to turn to the kitchen 92iii. to make sure ${ }^{(\mathbf{a})}$ 92iv. $\underline{\text { there }}^{(\mathbf{a})}$ is something for their breakfast. 93i. Right $\underline{\text { now }}^{(\mathbf{a})}$, I call out to Abiw 93ii. thatthe bathroom ${ }^{(\mathbf{b})}$ is clear, 93iii. $\underline{\text { sohe }}^{(\mathbf{b})}$ can have his bath 93iv. ifthe

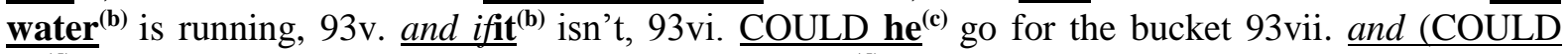
\left.${\underline{\mathbf{h e}^{(\mathrm{d})}}}^{\text {)take it to the water tank 93viii. and (COULD he }}{ }^{(\mathrm{d})}\right)$ fetch some water for his own bath, please, Mister? 94i. Depending on his mood ${ }^{(\mathbf{b})}$, 94ii. $\underline{\mathbf{A b i w}}^{(\mathbf{a})}$ immediately runs to the bathroom for the pail 


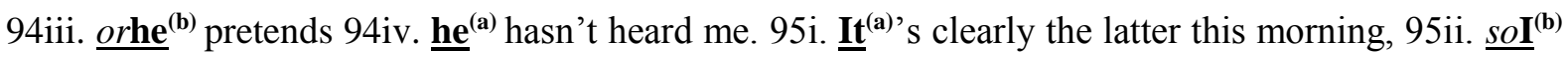

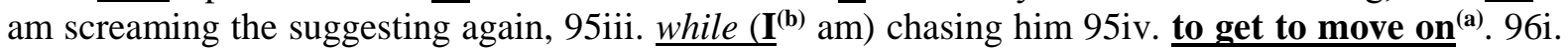
At some point $^{(\mathbf{a})}$ I can hear 96ii. my husband $^{(\mathbf{a})}$ (who is) waking up, 96iii. and (my husband $^{(\mathbf{b})}$ who

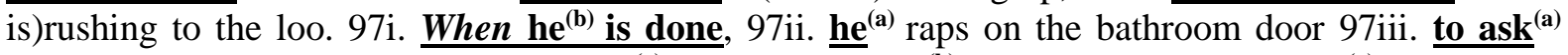

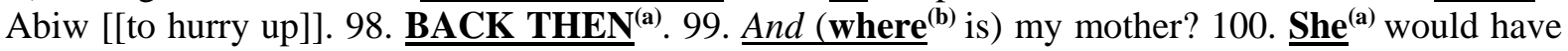
woken up a long time before Father. 101. A very long time ${ }^{(a)}$ (she would have woken up before Father). 102i. At least, that ${ }^{(\mathbf{b}) ' s}$ 102ii. how ${ }^{(\mathbf{a})}$ it seemed to me then. 103. In reality ${ }^{(\mathbf{a})}$, it may have been no more than half an hour, or even its quarter before. 104i. She ${ }^{(a)}$ would feed the baby, 104ii. $\underline{\text { whenthere }}^{(\mathbf{b})}$ was a baby to be fed, 104iii. and (she ${ }^{(\mathbf{b})}$ would) wash off the night's mess. 105i. All

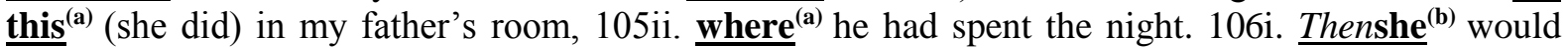
shake us awake, 106ii. ' us $^{\text {(a) }}$ being my brother Abaka, the firstborn, my older sister, Bosompra, and I, and later, the one 106iii. who ${ }^{(\mathbf{e})}$ turned to be our youngest. 107i.I ${ }^{(\mathbf{a})}$ remember now, 107ii. whenthe last one $^{(\mathbf{b})}$ was still a baby, 107iii. weolder ones ${ }^{(\mathbf{a})}$ had been banished from our father's room, 107iv. the $\underline{\text { two girls }}^{(\mathbf{a})}$ to sleep in our mother's room, $107 \mathrm{v}$. and Abaka $^{(\mathbf{b})}$ to join the other young male relatives in the big hall in the family house at the other end of the village, 107vi. where ${ }^{(\mathbf{a})}$ they used to raise the funeral bed 107vii. when ${ }^{(\mathbf{a})}$ any of Father's relatives died. 108. TODAY $\underline{\mathbf{Y}}^{(\mathrm{a})} \cdot 109 \mathrm{i}$. $\underline{\mathbf{I}}^{(\mathrm{a})}$ have put the kettle on 109ii. to make ${ }^{(\mathbf{a})}$ some coffee for him and tea for myself. 110i. $\underline{\mathbf{I}}^{(\mathbf{a})}$ 'll take his coffee to the bathroom, 110ii. orifit ${ }^{(\mathbf{b})}$ 's a morning 110iii. $\underline{\mathbf{h e}}^{(\mathbf{a})}$ feels like socializing, 110iv. $\underline{\mathbf{h e}}^{(\mathbf{a}) '} 11$ join me and the kids in the kitchen $110 \mathrm{v}$. so that whilethey ${ }^{(\mathbf{b})}$ are eating 110vi. $\underline{\text { he }}^{(\mathbf{a}) '} 11$ leisurely drink his coffee 110vii.

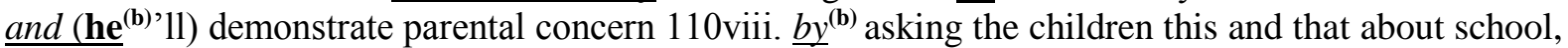
110ix. while $\mathbf{I}^{(\mathbf{b})}$ gulp down my tea 110x. and $\left(\mathbf{I}^{(\mathbf{b})}\right)$ try to hurry to the children back to their room for them 110xi. to assemble ${ }^{(\text {a) }}$ the contents of their schoolbags- 110xii. which $^{(\mathbf{e})}$ I didn't manage to check last night 110xiii. becausethere ${ }^{(\mathbf{b})}$ was no time, 110xiv. or becauseit ${ }^{(\mathbf{b})}$ occurred to me $110 \mathrm{xv}$. $\underline{\mathbf{t}}^{(\mathbf{a})}$ was rather late, 110xvi. $\operatorname{or} \underline{\underline{I}}^{(\mathbf{b})}$ was too tired and sleepy. 111 i. Eventually ${ }^{(\mathbf{a})}$ the kids are ready 111 ii. and $\underline{(t h e y}^{(\mathbf{b})}$ are) waiting. $112 \mathrm{i} . \underline{S O \mathbf{I}^{(\mathbf{b})}}{ }^{2}$ got back to the kitchen and the small pantry $112 \mathrm{ii}$. to check $^{(\mathbf{a})} 112 \mathrm{iii}$. $\underline{\text { what }}^{(\mathbf{a})}$ could be available for supper. 113i. That ${ }^{(\mathbf{b})}$ done, 113 ii. $\underline{\underline{I}}^{(\mathbf{a})}$ aim for the bathroom. 114i. $\underline{\mathbf{H e}}^{(\mathrm{a})}$ is in there 114ii. ( $\underline{\mathbf{h e}}^{(\mathbf{a})}$ is) whistling. 115i. $\underline{\mathbf{H e}}^{(\mathbf{a})}$ comes out, 115ii. $\underline{a s h}^{(\mathbf{b})}$ is on his way to the bedroom 115iii. $\underline{\text { and } \mathbf{m e}}^{(\mathbf{b})}$ to the bathroom, 115iv. $\underline{\mathbf{w}}^{(\mathbf{a})}$ collide. 116i. $\underline{\mathbf{H e}}^{(\mathbf{a})}$ asks me 116ii. whether $\mathbf{I}^{(\mathbf{b})}$ 'd put clothes out for him. 117i. When $\mathbf{I}^{(\mathbf{b})}$ say no, 117ii. and then $\left(\mathbf{I}^{(\mathbf{b})}\right)$ turn around 117iii. $\underline{\text { to hurry }}^{\text {back }}{ }^{(\mathbf{a})}$ to the bedroom ahead of him 117iv. to correct ${ }^{(\mathbf{a})}$ my mistake, $117 \mathrm{v}$. $\underline{\mathbf{I}}^{(\mathbf{a})}$ hear him $117 \mathrm{vi}$. $\underline{\underline{\mathbf{h e}}}^{(\mathbf{a})}$ is) muttering under his breath about [[how his friend's wives would not do that to their husbands]], 117vii. $\underline{\text { and }}^{(\mathbf{a}) '}$ 'm close to tears 117 viii. $\underline{\text { while }}^{(\mathbf{b})}$ pretending not to have heard him. $118 \mathrm{i}$. $\underline{\text { SoI }} \mathbf{I}^{(\mathbf{b})}$ 'm now in the bedroom 118ii. to put ${ }^{(\mathbf{a})}$ socks, pants, trousers, a singlet and a shirt out for him from a batch of clothes 118iii. that $\mathbf{I}^{(\mathbf{b})}$ had organized for the washman 118iv. to take away ${ }^{(\mathbf{a})}$ at the weekend, $118 \mathrm{v}$.

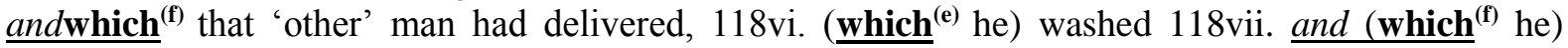
beautifully ironed. 119i. Thenit ${ }^{(\mathbf{b})}$ occurs to me, 119ii. that $\mathbf{I}^{(\mathbf{b})}$ might as well lay out some clothes for

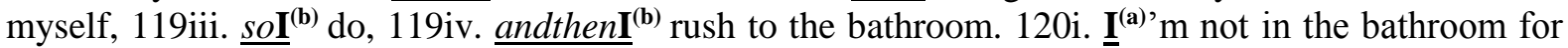
even ten minutes 120ii. whenthere ${ }^{(\mathbf{b})}$ 's severe rapping on the door, 120iii. and $\mathbf{I}^{(\mathbf{b})}$ hear the gruffest voice- [[whose owner I couldn't possibly know from anywhere in this world // and have definitely not met in any previous existence]] - 120iv. ( which $^{(\mathbf{e})}$ ) asking me [[when on earth I'll finish having my bath // 'because it's getting to half-past seven, // and we should have been on our way already.']] 121. $\underline{\text { BACK THEN }}^{(\mathbf{a})}$. 122i. Once ${ }^{(\mathbf{a})}$ we were awake, 122ii. thanks to $^{(\mathbf{b})}$ Mother's resilience and

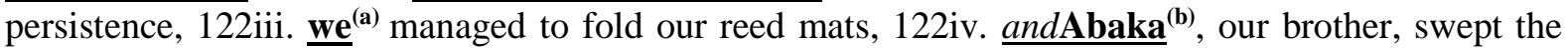
floor. 123. Thenwe ${ }^{(\bar{b})}$ followed my mother. 124i. $\underline{\mathbf{W e}}^{(\mathbf{a})}$ all walked across the courtyard to my mother's part of the compound 124ii. where ${ }^{(a)}$ the dirty pots and pans from the previous night's supper were waiting to be washed. 125i. $\underline{\mathbf{I}}^{(\mathbf{a})}$ imagine 125ii. $\underline{\text { Mother }}^{(\mathbf{a})}$ washed the pots 125 iii. $\underline{\text { beforewe }}^{(\mathbf{b})}$ were born 125iv. or untilwe ${ }^{(\mathbf{b})}$ became old enough [[to do them]]. 126i. $\underline{\mathbf{I}}^{(\mathbf{a})}$ never saw 126ii. Abaka $^{(\mathbf{a})}$ touch them, even once. 127i. $\underline{\mathbf{I t}}^{(\mathbf{a})}$ naturally fell to us girls, 127ii. from $\mathbf{I}^{(\mathbf{b})}$ believe 127iii. when $\mathbf{m y}$ older sister $^{(\mathbf{b})}$ Bosompra was just about old enough to stand upright, 127iv. and $\mathbf{I}^{(\mathbf{b})}$ was to join her $127 \mathrm{v}$. all the

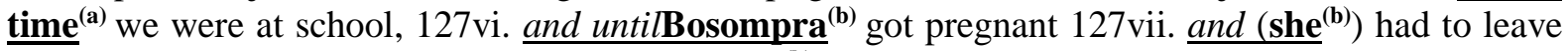
school [[to get married]], 127viii. andafterwards $^{(\mathbf{b})}$, until I left home [[to go to boarding school.]] 128. THIS MORNING ${ }^{(\mathbf{a})}$. 129i. $\underline{\mathbf{I}}^{(\mathbf{a})}$ don't say a word in reply or in my defence, $129 \mathrm{ii} . \underline{\text { butI }}^{(\mathbf{b})}$ notice 129iii. $\underline{\mathbf{I}}^{(\mathbf{a})}$ am shaking, 129iv. and $\left(\mathbf{I}^{(\mathbf{b})}\right.$ am) close to tears. 130i. When $\mathbf{I}^{(\mathbf{b})}$ finish 130ii. and $\left(\mathbf{I}^{(\mathbf{b})}\right)$ get out of the bathroom 130iii. $\underline{\mathbf{I}}^{(\mathbf{a})}$ find him 130iv. ( $\underline{\mathbf{h e}}^{(\mathbf{a})}$ is) sitting in front of the TV 130v. ${\underline{\left(\mathbf{h e}^{(\mathbf{a})}\right.}}^{\text {is) }}$ watching CNN Early Morning News 130vi. and $\left(\overline{\mathbf{h e}}^{(\mathbf{b})}\right.$ is) trying to follow the stock market. 131. $\underline{\text { On }}$ Wall Street $^{(a)}$, if you please. 132. Sitting in Oguaa, Ghana, watching the New York Stock 
Exchange andcommenting on the volatility or otherwise of NASDAQ $^{\text {(a) }}$ (are not African realities). 133i. $\underline{\mathbf{I}}^{(\mathbf{a})}$ mean, 133ii. who $^{(\mathbf{a})}$ has that kind of time in Africa and Ghana, 133iii. Before they ${ }^{(\mathbf{b})}$ go to work? 134. DOES that ${ }^{(\mathbf{c})}$ make sense? 135i. $\underline{\mathbf{I}}^{(\mathbf{a})}$ mean, 135ii. what ${ }^{(\mathbf{a})}$ does the wife of the man [[who's got that kind of time]] have? 136. Once again ${ }^{(\text {a) }}$, I'm close to tears. 137. BACK THEN ${ }^{(\mathbf{a})}$. 138i.

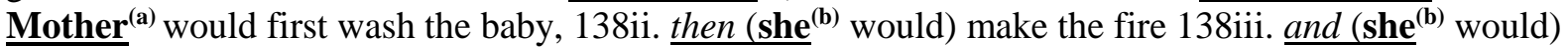
put the pot on [[to cook the corn porridge.]] 139. $A-h-h-h$, that porridge ${ }^{(\mathbf{b})}\left(\right.$ is unforgettable). 140i. $\underline{\mathbf{I}}^{\text {(a) }}$ remember 140ii. the way ${ }^{(\mathbf{a})}$ it bubbled 140iii. While she ${ }^{(\mathbf{b})}$ quickly took her half-bucketful of water to the bamboo bathroom [[to wash herself.]] 141i. She ${ }^{(\text {a) }}$ came [[running]] 141ii. When she ${ }^{(\mathbf{b})}$ had finished, 141iii. And on her way ${ }^{(\mathbf{b})}$ (she) stopped by the fire [[to check it.]] 142. Always $^{(\mathbf{a})}$. 143i. $\underline{\text { She }}^{(a)}$ never seemed to miss the routine even once 143ii. all the time ${ }^{(a)}$ we were growing up. 144i. $\underline{\text { She }}^{(a)}$ would then rush indoors [[to oil her arms and legs // and powder the rest of her body, // then get into her farm clothes,]] 144ii. after whichshe ${ }^{(\mathbf{b})}$ asked Bosompra or me [[to go round the corner to Auntie Araba's for bread.]] 145i. When we ${ }^{(\mathbf{b})}$ brought it, 145ii. she ${ }^{(\mathbf{a})}$ would dish out the porridge. 146. And where $^{(\mathbf{b})}$ was our oldest, our brother Abaka, all that time? 147i. PLEASE, don' $\mathbf{t}^{(\mathbf{c})}$ ask me, 147ii. $\underline{I}^{(\mathbf{a})}$ don't know. 148. $\underline{\mathbf{I}}^{(\mathbf{a})}$ didn't know even then. 149i. Once we $\mathbf{e}^{(\mathbf{b})}$ left our father's room, 149ii. Abaka $^{(\mathbf{a})}$ never seemed to be around at all, 149iii. except when it $^{(\mathbf{b})}$ was time [[for Mother to dish out the porridge and bread]], 149iv. And later in the evening ${ }^{(\mathbf{b})}$, when supper was ready to eat. 150 . As for household chores $^{(\text {a) }}$, he had one, and one only. 151. Sweeping our father's room ${ }^{\text {(a) }}$ (it is!). 152 . $\underline{\text { How many }}^{(\mathbf{a})}$ chores did each of us girls have? 153. $\underline{\text { My sister }}^{(\mathbf{a})}$, don't ask me to count them. 154. $\underline{\mathbf{Y o u}}^{(\mathbf{a})}$ too are a girl. 155. $\underline{\mathbf{Y o u}}^{(\mathbf{a})}$ know. 156i. ' $\underline{\mathbf{I}}^{(\mathbf{a})}$ am the ONLY ONE they send around here,' $156 \mathrm{ii}$. $\underline{\text { complained }}^{(\mathbf{a})}$ my only child, a daughter. 157. $\underline{\mathbf{I}}^{(\mathbf{a})}$ did not laugh. 158. (This ${ }^{(\mathbf{a})}$ is) Not because of her poor siblingless state. 159. $\underline{\mathbf{I}}^{\text {(a) }}$ was thinking that Miss Why?-Why?-Why? 160i. $\left(\underline{\text { Miss }}^{(\mathbf{a})}\right.$ ) Could have had more than enough reason to sing the same song, 160ii. even if she $^{(\mathbf{b})}$ had had eleven brothers. 161i. By the way ${ }^{(\mathbf{a})}$, I am beginning to vaguely remember 161ii. That if Abaka $^{(\mathbf{b})}$ occasionally wandered by the cooking area, 161 iii.Mother ${ }^{(\mathbf{a})}$, or some other older woman, would shoo him away, 161iv. with the threat ${ }^{(a)}$ that "the boy [[who insisted on stirring the boiling pot]] was the one [[who grew into the beardless man.]]' 162 i. $\underline{(}^{(\mathbf{a})}$ don't remember 162 ii. Mother or Father ${ }^{(\mathbf{a})}$ eating any of the porridge or anything else in the morning. 163i. But $\mathbf{I}^{(\mathbf{b})}$ remember 163ii. that $\mathbf{s h e}^{(\mathbf{b})}$ hurried us on [[to finish our meal]], 163iii. and (she ${ }^{(\mathbf{b})}$ ) hurried us on [[to have our baths]], one after the other, 163iv. with the water $^{(\mathbf{a})}$ that we had fetched the evening before from the stream, 163v. and therefore $\left(\mathbf{i t}^{(\mathbf{b})}\right)$ was very cold. 164 i. $\underline{\mathbf{I}}^{(\mathbf{a})}$ can still feel 164ii. and $\left(\mathbf{I}^{(\mathbf{b})}\right)$ hear my teeth [[chattering down the years]] 164iii. Until $\mathbf{I}^{(\mathbf{b})}$ went to boarding school, 164iv. where ${ }^{(\mathbf{a})}$ the water [[that came from the pipes]] was warmer. 165i. OF COURSE, it $\mathbf{t}^{(\mathrm{c})}$ was Mother $165 \mathrm{ii} . \underline{\text { who }}^{(\mathrm{e})}$ helped us find our uniforms and our books, 165iii. and then $\left(\mathbf{w h o}^{(\mathbf{f})}\right)$ saw to it 165iv. Tha twe ${ }^{(\mathbf{b )})}$ were really, really out of the house and on our way to school, 165v. After $\mathbf{w e}^{(\mathbf{b})}$ had agreed on [[where she would hide her keys for the day.]] 166i. From all the Saturdays ${ }^{(\mathbf{a})}$ we didn't go to school, 166ii. $\underline{\mathbf{w e}}^{(\mathrm{a})}$ learnt that after packing us off, 166iii. she $^{(\mathbf{a})}$ would then go to the market 166iv. to buy ${ }^{(\mathbf{a})}$ kenkey and fried fish, tomatoes, onions and fresh peppers, 166v. when she ${ }^{(\mathbf{b})}$ didn't already have any of these items at home, 166vi. And once $^{(\mathbf{b})}$ she was back, 166vii. ( $\underline{\text { she }}^{(\text {a) }}$ would) wash the grinding stone, 166viii. ( $\underline{\text { she }}^{(\text {a) }}$ would) grind the vegetables together with salt, 166ix. which ${ }^{(\mathbf{e})}$ she later packed for Father's lunch and her own, 166x. $\underline{\text { meanwhile }}^{(\mathbf{b})}$ having also had to remember $166 x$ i. to look $^{(\mathbf{a})}$ for the old gallon cooking-oil tin, 166xii. $\underline{\text { fill }}^{(\text {a) }}$ it with water, 166xiii. And add $^{(b)}$ it to the other items already on the wooden tray, 166xiv. And place $^{(\mathbf{b})}$ the tray on the head. 167i. Always ${ }^{(\mathbf{a})}$, always, always, at this stage, with only his machete under his arm, Father would stroll across the courtyard 167ii. and, with barely suppressed irritation $^{(\mathbf{b})}$, say to Mother, 167iii. ' $\underline{I}^{(\mathbf{a})}$ have been ready to go for these past hours. 168i. $\underline{\text { No one }}^{(\mathbf{a})}$ can call himself a farmer 168ii. if he $^{(\mathbf{b})}$ sets out for his farm 168iii. After the sun ${ }^{(\mathbf{b})}$ has appeared to dry off the dew. 169. Esi Achin ${ }^{(\mathbf{a})}$, what have you being doing ALL MORNING? 170. Why ${ }^{(\mathbf{a})}$ are you women so tardy?!' 171i. Throughout my childhood ${ }^{(\mathrm{a})}$, those were the first, last, and the only words $171 \mathrm{ii} . \underline{\underline{I}}^{(\mathrm{a})}$ heard 171iii. my father ${ }^{(\mathbf{m})}$ speak to my mother in the morning.172. ( $\underline{\mathbf{H e}}^{(\mathbf{a})}$ did so) Every morning, except for two days in the week. 173i. Dear Father ${ }^{(\mathbf{a})}$, please forgive me 173ii. If $\mathbf{i t}^{(\mathbf{b})}$ wasn't so. 174i. $\underline{\mathbf{I}}^{(\mathbf{a})}$ admit 174ii. That memory ${ }^{(\mathbf{b})}$ is not only selective, but sometimes quite faulty. $175 \mathrm{i}$. Although $\mathbf{w e}^{(\mathbf{b})}$ have each got the memory $175 i i$. we ${ }^{(\mathbf{a})}$ 've got, 175iii. And that ${ }^{(\mathbf{b})}$ 's $175 \mathrm{iv}$. The only one ${ }^{(\mathbf{a})}$ we can trust ... 176i. Those ${ }^{(\mathbf{a})}$ were the ordinary mornings, 176ii. And there ${ }^{(\mathbf{b})}$ were not many such in my

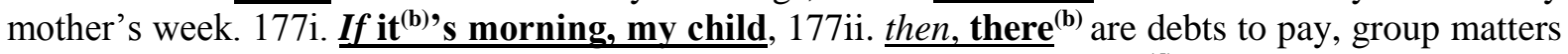
to meet about, community work to do, in kind or cash. 178 . And ISN'T it ${ }^{(\mathrm{d})}$ strange sometimes about night and rest and sleep and waking up to the body's whimpers and wails and screams? 179i. $\underline{\text { So }}$ 
$\underline{\text { here }}^{(\mathbf{b})}$ are the numbers to count, young or old, 179ii. $\underline{\text { there }}^{(\mathbf{a}) \text { 's the sick 179iii. to tend to }}{ }^{(\mathbf{a})} 179 \mathrm{iv}$.

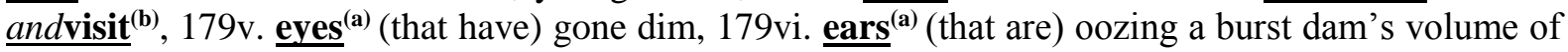
putrefaction; 179vii. the sore throat ${ }^{(\text {a) }}$ (that is to be taken) to the clinic; the priest, the priestess, marabout and hospital ... 179viii. $\underline{\operatorname{orsomeone}}^{(\mathbf{b})}$ just fell into the well 179ix. and (s/he ${ }^{(\mathbf{b})}$ was)

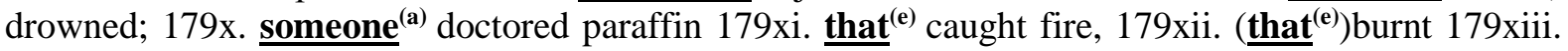
and $\left(\right.$ that $\left.^{(\mathbf{f})}\right)$ killed. 180i. I $f$ it $^{(\mathbf{b}) \text { 's morning, my child, }}$ 180ii. there ${ }^{(\mathbf{a})}$ are the dead [[for women to dress up, // to mourn, // to bury, // to celebrate.]] 181i. And when life ${ }^{(\mathbf{b})}$ is good, 181 ii. there ${ }^{(\mathrm{a})}$ 's the biggest harvest in living memory [[to wake up for at dawn, // cooking for the annual feast, of the old New Year, Christmas, Idd, the new New Year, // marriage to negotiate, a newborn in the neighbourhood.]]

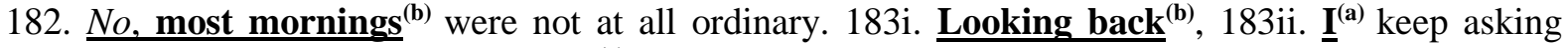
myself how Mother managed. 184. $\underline{\mathbf{I t}}^{(\mathbf{a})}$ couldn't have been humanly possible to be that busy. 185. Unless one $^{(\mathbf{b})}$ counted Thursdays and Sundays. 186i. On Thursday ${ }^{(\mathbf{a})}$, my parents did not go to the

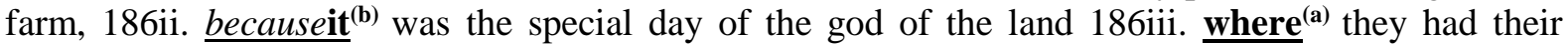
farms. 187. On Sunday ${ }^{(a)}$, we all went to church, Mother more regularly than Father. 188. And OF COURSE, $\mathbf{w e}^{(\mathbf{d})}$ had some necessary prodding from Mother. 189. THIS MORNING ${ }^{(\mathbf{a})}$. 190i. When all the financial news ${ }^{(b)}$ [he wants to hear] has been read out, 190ii. (it ${ }^{(a)}$ has been) fully illustrated 190iii. and $\left(\mathbf{i t}^{(\mathbf{b})}\right.$ has been) commented upon, 190iv. he ${ }^{(\mathbf{a})}$ gets up abruptly, 190v. and $\mathbf{I}^{(\mathbf{b})}$ swear 190vi. $\underline{\mathbf{I}}^{\text {(a) }}$ can feel 190vii. his legs ${ }^{\text {(a) }}$ (that are) shaking with irritation inside his trousers. 191.

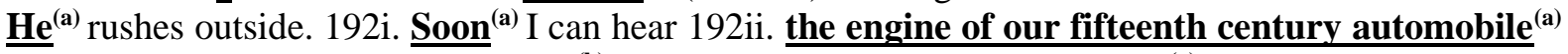
(that is) wheezing 192iii. and (it $^{(\mathbf{b})}$ is) spluttering into life. 193i. $\underline{\mathbf{I}}^{(\mathbf{a})}$ can also hear 193ii. children $^{(\mathbf{a})}$ (who are) running out to the car. 194i. $\underline{\mathbf{I}}^{(\mathbf{a})}$ ' $\mathrm{m}$ all dressed, 194ii. $\underline{\text { and } \mathbf{m y}}_{\text {hair }}{ }^{(\mathbf{b})}$ is combed out.195i. In spite of everything ${ }^{(\mathbf{b})}$ (that happened), 195ii. $\underline{\mathbf{I}}^{(\mathbf{a})}$ managed to get my hair done over the weekend at the salon, 195iii. and now $^{(\mathbf{b})}$ I'm wishing $195 \mathrm{iv}$. $\underline{\mathbf{I}}^{(\mathbf{a})}$ ' $\mathrm{d}$ time to give my thick but obedient hair $195 \mathrm{v}$. a little more attention ${ }^{(\mathbf{a})}$ it deserves. 196i. Instead ${ }^{(\text {a) }}$, I pick up my handbag and carry-all 196ii. in which ${ }^{(\mathrm{e})}$ I normally haul around all my troubles, commitments, and half of the known universe. 197i. That ${ }^{(\mathbf{a})}$ 's 197ii. when ${ }^{(\mathbf{a})}$ the phone rings, 197iii. $\underline{\text { and }}^{\mathbf{( b )}}{ }^{\text {') }}$ ve decided not to answer 197iv.

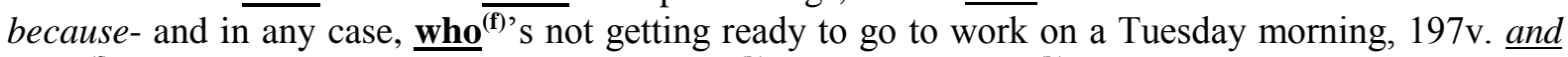

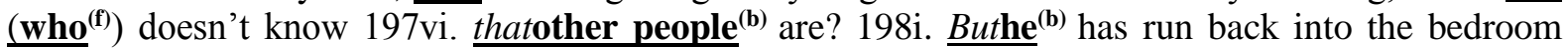
198ii. to pick $^{(\mathbf{a})}$ up the receiver 198iii. and $\left(\mathbf{h e}^{(\mathbf{b})}\right)$ is busy $198 \mathrm{iv}$. (he $^{(\mathbf{a})}$ is) doing his 'ah no' 'ah yes' into it. 199. Only those two syllasomething responses ${ }^{(\mathbf{a})}$ (it is!). 200. As ifthe person at the other

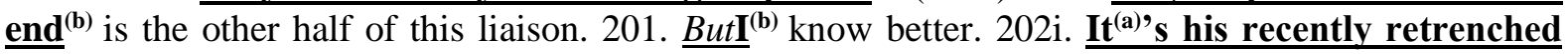
older brother 202ii. who ${ }^{(\mathbf{e})}$ is back in the village 202iii. ( $\underline{\mathbf{w h o}}^{(\mathbf{e})}$ is) trying to farm with his settlement, 202iv. and (who ${ }^{(\mathbf{f})}$ is) doing the most ridiculously poor job of it, 202v. andright now ${ }^{(\mathbf{b})}$ (he) is phoning to tell him 202vi. he ${ }^{(\mathbf{a})}$ needs help badly, 202vii. $\underline{\operatorname{In} \text { facthe }}{ }^{(\mathbf{b})}$ just got off the tro-tro, 202viii. andhe $^{(\mathbf{b})}$ is at the station, 202ix. so COULD one of us ${ }^{(\mathbf{d})}$ bring him home? 203i. And $\mathbf{I}^{(\mathbf{b}) '} \mathrm{~m}$ right $203 \mathrm{ii}$. becausemy $\underline{\text { husband }}^{(\mathbf{b})}$ is now trying to string some decent sentences together, 203iii. ( $\underline{\mathbf{h e}}^{(\mathbf{a})}$ is) telling his brother 203iv. thatwe ${ }^{(\mathbf{b})}$ are late for work, 203v. andthe children ${ }^{(\mathbf{b})}$ (are late) for school, 203vi. so COULD his brother $^{(\mathbf{d})}$ come 203vii. and (COULD he ${ }^{(\mathrm{d})}$ ) wait at the neighbours'. 204i. In the meantime ${ }^{(\mathbf{a})}$, he'll

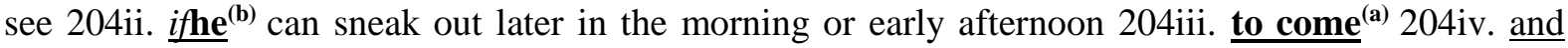
$\underline{\text { meet }}^{(\mathbf{b})}$ him. 205i. I $\underline{\mathbf{I}}^{(\mathbf{a})}$ ve been waiting for him 205ii. $\underline{\text { to finish }}^{(\mathbf{a})}$ the telephone discussion. 206. $\underline{\mathbf{H e}}^{(\mathbf{a})}$ replaces the receiver. 207i. The phone ${ }^{(a)}$ rings again immediately 207ii. $\underline{\text { and this time }}^{(\mathbf{b})}$ he ignores it

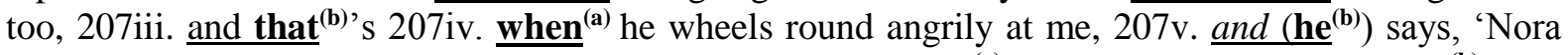
Cobbina,' - only my full maiden name at such times - 207vi. $\underline{\mathbf{I}}^{(\mathbf{a})}$ 've been ready $207 \mathrm{vii}$. and $\underline{(\mathbf{I}}^{(\mathbf{b})}$ have been) waiting to leave for my office these past several hours. $208 \mathrm{i}$. $\underline{\operatorname{Remember}}^{(\mathbf{a})}, 208 \mathrm{ii} \underline{\mathbf{I}}^{(\mathbf{a})}$ am not a self-employed man, 208iii. $\underline{\text { but }\left(\mathbf{I}^{(\mathbf{b})} \text { am) a civil servant. 209. At leastyou }\right.}{ }^{(\mathbf{b})}$ work with a private organization. 210i. Soyour boss ${ }^{(\mathbf{b})}$ is a human being 210ii. you $^{(\mathbf{a})}$ can explain things to.' 211i. 'Since

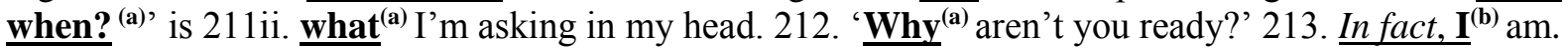
214. 'What ${ }^{(\mathbf{a})}$ have you been doing ALL MORNING? 215. Andby the way ${ }^{(\mathbf{b})}$, why are women so

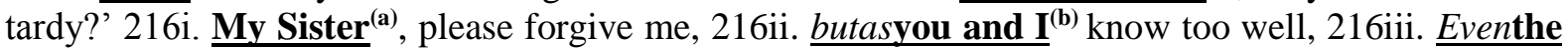
better times $^{(\mathbf{b})}$ are just an American-style 'good news, bad news' kind of tale: cooking for the annual feast of Christmas, Idd, the New Year; the car for the workshop; airline tickets to buy; a wedding to plan for, or its anniversaries; birthdays to remember, plan for and execute; students off to boarding school ... 217i. My Sister ${ }^{(\text {a) }}$, those pepper pastes take a hell of a time to cook 217ii. sothey ${ }^{(\mathbf{b}) '}$ 'll keep ... 217iii. orit ${ }^{(\mathbf{b})}$ 's just the lists, 217 iv. those lists ${ }^{(\mathbf{a})}$ we have to put together for ' $n$ ' that, everything and all, every morning. 218i. Now ${ }^{(\text {a) }} I^{\prime} m$ sitting in the passenger seat 218ii. $\left(\underline{\mathbf{I}}^{(\mathbf{a})}\right.$ am) watching his face,

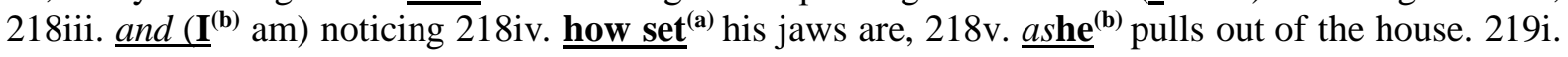




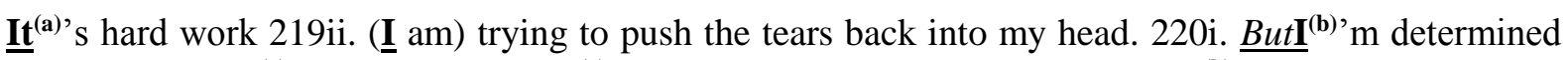

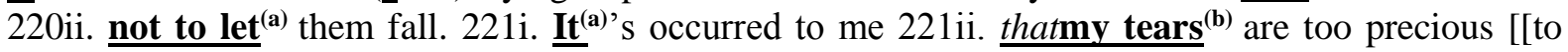
waste.]] 222i. $\underline{S} \mathbf{I}^{(\mathbf{b})}$ open my eyes wide 222ii. and $\left(\mathbf{I}^{(\mathbf{b})}\right)$ stare ahead, 222iii. $\left(\underline{\mathbf{I}}^{(\mathbf{a})}\right.$ am) aware $222 \mathrm{iv}$. thatmy day $^{(\mathbf{b})}$ is ruined. 223i. $A-h-h-h$, here $^{(\mathbf{b})}$ is Mother's face, 223ii.(itit ${ }^{(\mathbf{a})}$ is) swimming into focus,

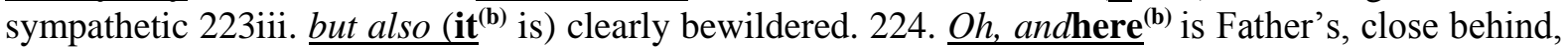
a little self-satisfied, almost triumphant? 225i. That ${ }^{(\mathbf{a})}$ 's 225 ii. when ${ }^{(\mathbf{a})}$ this cheeky idea occurs to me. 226i. That perhaps even the best proverbs ${ }^{(\mathbf{a})}$ cannot apply in all situations, 226ii. ${ }_{\text {but }}\left(\right.$ they $^{(\mathbf{b})}$ can apply) only to specific places and particular times. 227 i. So although the ancestors ${ }^{(\mathbf{b})}$ may not agree with me, 227ii. $\underline{\mathbf{I}}^{(\mathbf{a})}$ think, 227iii. and $\left(\mathbf{I}^{(\mathbf{b})}\right)$ want to tell the whole world, 227iv. That sometimes ${ }^{(\mathbf{b})}$ a crab can father a bird, 227v. andat other times $^{(\mathbf{b})}$, well ...

\section{Analysis of the Theme-types and Thematic Structure in the Short Story}

The table below presents the Theme-types identified in the short story under scrutiny.

Table2. Distribution of Theme-types in the Short Story.

\begin{tabular}{|c|c|c|c|}
\hline $\begin{array}{l}\text { Theme } \\
\text { class }\end{array}$ & Clause numbers & $\begin{array}{l}\text { Frequency } \\
\text { rate }\end{array}$ & $\begin{array}{l}\text { Percentage } \\
(\%)\end{array}$ \\
\hline (a) & $\begin{array}{l}\text { 1ii, 2ii, 4, 5, 6, 7, 8, 9, 11i, 11iv, 14i, 15ii, 16i, 17, 18, 19, } \\
\text { 20, 21, 22, 23ii, 25i, 26ii, 28iii, 29, 30, 31, 33ii, 34i, 34ii, } \\
\text { 35, 36, 37, 39ii, 40, 41ii, 42, 43, 44, 45, 46, 47i, 48, 49, } \\
\text { 50iii, 50iv, 51i, 51ii, 55, 56, 58, 59ii, 60, 62ii, 63, 64, 65, } \\
\text { 66, 70ii, 70iv, 75ii, 77i, 77iii, 77v, 77viii, 78i, 78v, 79ii, } \\
\text { 80ii, 80iv, 81, 82i, 82ii, 82iii, 82v, 82vi, 82viii, 82ix, 83, } \\
\text { 84v, 84vi, 85i, 85ii, 87iii, 88, 89, 90ii, 91i, 91ii, 92i, } \\
\text { 92iii, 92iv, 93i, 94ii, 94iv, 95i, 95iv, 96i, 96ii, 97ii, 97iii, } \\
\text { 98, 100, 101, 102ii, 103, 104i, 105i, 105ii, 106ii, 107i, } \\
\text { 107iii, 107iv, 107vi, 107vii, 108, 109i, 109ii, 110i, 110iii, } \\
\text { 110iv, 110vi, 110xi, 110xv, 111i, 112ii, 113ii, 114i, 114ii, } \\
\text { 115i, 115iv, 116i, 117iii, 117iv, 117v, 117vi, 118ii, 118iv, } \\
\text { 120i, 121, 122i, 122iii, 124i, 124ii, 125i, 125ii, 126i, } \\
\text { 126ii, 127i, 127v, 128, 129i, 129iii, 130iii, 130iv, 130v, } \\
\text { 131, 132, 133i, 133ii, 135ii, 136, 137, 138i, 140ii, 141, } \\
\text { 142, 143i, 143ii, 144i, 145i, 145ii, 147ii, 148, 149ii, 150, } \\
\text { 151, 152, 153, 154, 155, 156i, 156ii, 157, 158, 159, 160i, } \\
\text { 161i, 161iii, 161iv, 162i, 162ii, 163iv, 164i, 164iv, 166i, } \\
\text { 166ii, 166iii, 166iv, 166vii, 166viii, 166xi, 166xii, 167i, } \\
\text { 168i, 169, 170, 171i, 171ii, 171iii, 172, 173i, 174i, 175ii, } \\
\text { 175iv, 176i, 179ii, 179iii, 179v, 179vi, 179vii, 179x, } \\
\text { 180ii, 181ii, 183ii, 184, 186i, 186iii, 187, 189, 190ii, } \\
\text { 190iv, 190vi, 190vii, 191, 192i, 192ii, 193i, 193ii, 194i, } \\
\text { 195ii, 195iv, 195v, 196i, 197i, 197ii, 198ii, 198iv, 199, } \\
\text { 202i, 202vi, 203iii, 204i, 204iii, 205i, 205ii, 206, 207i, } \\
\text { 207iv, 207vi, 208i, 208ii, 210ii, 211i, 211ii, 212, 214, } \\
\text { 216i, 217i, 217iv, 218i, 218ii, 218iv, 219i, 219ii, 220ii, } \\
\text { 221i, 222iii, 223ii, 225i, 225ii, 226i, 227ii. }\end{array}$ & 287 & 52.27 \\
\hline (b) & $\begin{array}{l}\text { 10i, 10ii, 11ii, 13, 15i, 15iii, 15iv, 15v, 15vi, 16ii, 23i, } \\
\text { 25ii, 26i, 28i, 28ii, 33i, 38, 39i, 47ii, 50i, 50ii, 53i, 53ii, } \\
\text { 57, 59i, 61, 62i, 68, 70i, 70iii, 75i, 78iii, 78iv, 89iii, 80i, } \\
80 \mathrm{iii}, 80 \mathrm{vi}, 82 \mathrm{vii}, 84 \mathrm{i}, 84 \mathrm{ii}, 84 \mathrm{iii}, 84 \mathrm{iv}, 85 \mathrm{iii}, 85 \mathrm{iv}, 86,87 \mathrm{i}, \\
87 \mathrm{ii}, 87 \mathrm{v}, 92 \mathrm{i}, 93 \mathrm{ii}, 93 \mathrm{iii}, 93 \mathrm{iv}, 93 \mathrm{v}, 94 \mathrm{i}, 94 \mathrm{iii}, 95 \mathrm{ii}, 95 \mathrm{iii}, \\
96 \mathrm{iii}, 97 \mathrm{i}, 99,102 \mathrm{i}, 104 \mathrm{ii}, 104 \mathrm{iii}, 106 \mathrm{i}, 107 \mathrm{ii}, 107 \mathrm{v}, 110 \mathrm{ii}, \\
110 \mathrm{v}, 110 \mathrm{vii}, 110 \mathrm{viii}, 110 \mathrm{ix}, 110 \mathrm{x}, 110 \mathrm{xiii}, 110 \mathrm{xiv}, \\
110 \mathrm{xvi}, 111 \mathrm{ii}, 112 \mathrm{i}, 113 \mathrm{i}, 115 \mathrm{ii}, 115 \mathrm{iii}, 116 \mathrm{ii}, 117 \mathrm{i}, 117 \mathrm{ii}, \\
117 \mathrm{vii}, 117 \mathrm{viii}, 118 \mathrm{i}, 118 \mathrm{iii}, 119 \mathrm{i}, 119 \mathrm{ii}, 119 \mathrm{iii}, 119 \mathrm{iv}, \\
120 \mathrm{ii}, 120 \mathrm{iii}, 122 \mathrm{ii}, 122 \mathrm{iv}, 123,125 \mathrm{iii}, 125 \mathrm{iv}, 127 \mathrm{ii}, \\
127 \mathrm{iii}, 127 \mathrm{iv}, 127 \mathrm{vi}, 127 \mathrm{vii}, 127 \mathrm{viii}, 129 \mathrm{ii}, 129 \mathrm{iv}, 130 \mathrm{i}, \\
130 \mathrm{ii}, 130 \mathrm{vi}, 133 \mathrm{iii}, 139,140 \mathrm{iii}, 141 \mathrm{ii}, 141 \mathrm{iii}, 144 \mathrm{ii}, 145 \mathrm{i}, \\
146,149 \mathrm{i}, 149 \mathrm{iii}, 149 \mathrm{iv}, 160 \mathrm{ii}, 161 \mathrm{ii}, 163 \mathrm{i}, 163 \mathrm{ii}, 163 \mathrm{iii}, \\
163 \mathrm{v}, 164 \mathrm{ii}, 164 \mathrm{iii}, 165 \mathrm{iv}, 165 \mathrm{v}, 166 \mathrm{v}, 166 \mathrm{vi}, 166 \mathrm{x}, \\
166 \mathrm{xiii}, 166 \mathrm{xiv}, 167 \mathrm{ii}, 168 \mathrm{ii}, 168 \mathrm{iii}, 173 \mathrm{ii}, 174 \mathrm{ii}, 175 \mathrm{i},\end{array}$ & 205 & 37.34 \\
\hline
\end{tabular}




\begin{tabular}{|c|c|c|c|}
\hline & $\begin{array}{l}\text { 175iii, 176ii, 177i, 177ii, 179i, 179iv, 179viii, 179ix, } \\
\text { 180i, 181i, 182, 183i, 185, 186ii, 190i, 190iii, 190v, } \\
\text { 192iii, 194ii, 195i, 195iii, 197iii, 197vi, 198i, 198iii, 200, } \\
\text { 201, 202v, 202viii, 202vii, 203i, 203ii, 203iv, 203v, 204ii, } \\
\text { 204iv, 207ii, 207iii, 207v, 207vii, 208iii, 209, 210i, 213, } \\
\text { 215, 216ii, 216iii, 217ii, 217iii, 218iii, 218v, 220i, 221ii, } \\
\text { 222i, 222ii, 222iv, 223i, 223iii, 224, 226ii, 227i, 227iii, } \\
\text { 227iv, 227v. }\end{array}$ & & \\
\hline (c) & $\begin{array}{l}\text { 1i, 12, 24, 32, 54, 69, 76, 93vi, 134, 147i, 165i, 203vi, } \\
\text { 203vii. }\end{array}$ & 13 & 02.36 \\
\hline (d) & $\begin{array}{l}\text { 2i, 3, 27, 78ii, 79i, 87iv, 90i, 93vii, 93viii, 178, 188, } \\
\text { 202ix. }\end{array}$ & 12 & 02.18 \\
\hline (e) & $\begin{array}{l}\text { 11iii, 41i, 47iii, 52, 68, 77ii, 77iv, 77vi, 77vii, 82iv, } \\
\text { 106iii, 110xii, 118vi, 120iv, 165ii, 166ix, 179xi, 179xii, } \\
\text { 196ii, 202ii, 202iii. }\end{array}$ & 21 & 03.82 \\
\hline (f) & 118v, 118vii, 165iii, 179xiii, 197iv, 197v, 202iv. & 07 & 01.27 \\
\hline (g) & $71,72,73,74$. & 04 & 00.72 \\
\hline
\end{tabular}

In order to make the data in the table above more comprehensible and easily interpretable, the piechart below is provided to show how the different Theme-types are distributed across the story.

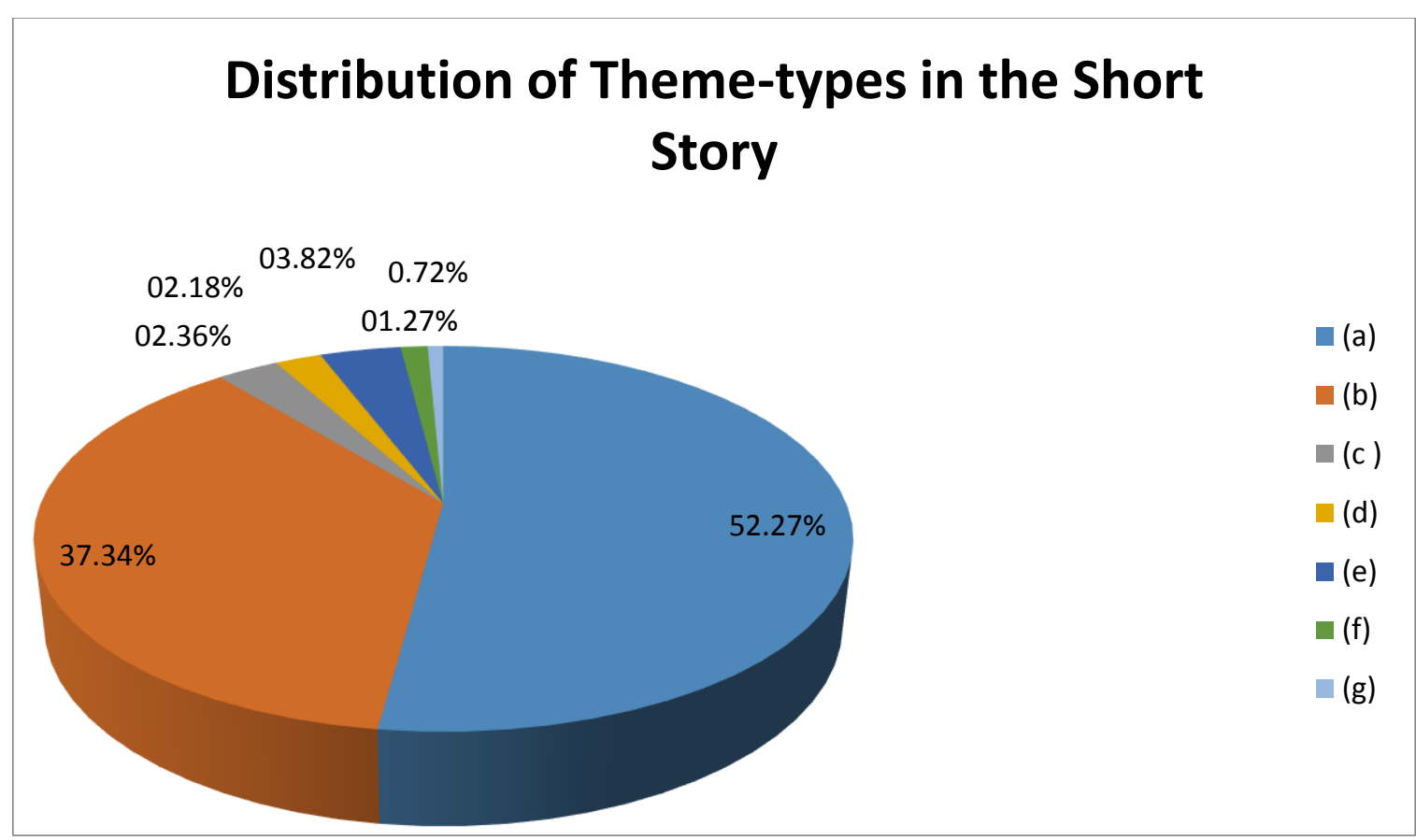

Figure1. Distribution of Theme-types in the Short Story.

As the table as well as the pie chart above shows, class (a) prevails over other classes in this story with a figure of $\mathbf{2 8 7 / 5 4 9}$ (i.e., $52.27 \%$ ). This simply denotes that this text is basically rife with clauses whose subjects occupy their usual, normal or expected slots. This is to say, these Themes are unmarked. However, they are assigned a Transitivity function (participant (1ii, 2ii 4, 5, 6, 7, 8, 9, 11i, 11iv, 14i, 15ii, 16i, 17, 19, 20, 21, 22, 25i, 26ii, 28iii, 29, 30, 31, 33ii, 34i, 34ii, 36, 37, 39ii, 40, 41ii, $42,43,44,45,46,47 \mathrm{i}, 48,49,50 \mathrm{iii}, 51 \mathrm{i}, 51 \mathrm{ii}, 55,56,58,62 \mathrm{ii}, 63,64,65,66,70 \mathrm{ii}, 70 \mathrm{iv}, 77 \mathrm{v}, 78 \mathrm{i}, 78 \mathrm{v}$, 79ii, 80iv, 82i, 82ii, 82v, 82vi, 82ix, 85i, 85ii, 88, 89, 91i, 92ii, 94ii, 94iv, 95i, 96ii, 97ii, 100, 102, 104i, 105i, 106ii, 107i, 107iv, 109i, 110i, 110iii, 110iv, 110vi, 110xv, 112iii, 113ii, 114i, 114ii, 115i, $115 \mathrm{iv}, 116 \mathrm{i}, 117 \mathrm{v}, 117 \mathrm{vi}, 117 \mathrm{vii}, 120 \mathrm{i}, 122 \mathrm{iii}, 124 \mathrm{i}, 125 \mathrm{i}, 125 \mathrm{ii}, 126 \mathrm{i}, 126 \mathrm{ii}, 127 \mathrm{i}, 129 \mathrm{i}, 129 \mathrm{iii}, 1130 \mathrm{iii}$, 130iv, 130v, 132, 133i, 133ii, 135i, 135ii, 138i, 140i, 140ii, 141i, 143i, 144i, 145ii, 147ii, 148, 149ii, 151, 152, 153, 154, 155, 156i, 157, 158, 159, 160i, 161iii, 162i, 162ii, 164i, 166ii, 166iii, 166vii, 166viii, 167iii, 168i, 169, 170, 171ii, 171iii, 172, 173i, 174i, 175ii, 175iv, 176i, 179ii, 179v, 179vi, 179vii, 179x, 180ii, 181ii, 183ii, 184, 190ii, 190iv, 190vii, 191, 192ii, 193i, 194i, 195ii, 195iv, 195v, 197i, 198iv, 199, 202i, 202vi, 203iii, 205i, 206, 207i, 207vi, 208ii, 210ii, 211ii, 212, 214, 216i, 217i, 217iv, 218ii, 218iv, 219i, 219ii, 221i, 222iii, 223ii, 225i, 226i and 227ii) (i.e., 71.42\%), process (14ii, 23ii, 50iv, 82iii, 84v, 84vi, 87iii, 90ii, 91ii, 92iii, 95iv, 97iii, 109ii, 110xi, 112ii, 117iv, 118ii, 118iv, 
156ii, 166iv, 169xi, 169xii, 179iii, 198ii, 204iii, 205ii, 208i and 220ii) (i.e., 10.10\%) and circumstance $(18,35,60$, 59ii, 60, 75ii, 77i, 77iii, 77viii, 80ii, 81, 82viii, 83, 93i, 96i, 98, 101, 103, 105ii, 107vi, 107vii, 108, 111i, 121, 122i, 124ii, 127v, 128, 131, 136, 137, 142, 143ii, 150, 161i, 161iv, 163iv, 164iv, 166i, 167i, 171i, 186i, 186iii, 187, 189, 192i, 196i, 197ii, 204i, 207iv, 211i, 217i, 218 and 225ii (i.e., 18.46\%)). It should be noted however that some of these topical Themes are ellipsed in some clauses (15iv; 15iv; 24; 25ii; 38; 44; 45; 53ii; 56; 63; 64; 67; 70iii; 78iii; 78iv; 78v; 80iv; 80v; 80vi; 82ii; 82v; 85iv; 95iii; 96iii; 99; 104iii; 110vii; 111ii; 114ii; 117ii; 117vi; 118vi; $118 \mathrm{vii}$; 120iv; 127vii; 130ii; 130iv; 130v; 130vi; 138ii; 138iii; 158; 160i; 163iii; 163v; 164ii; 165iii; 166vii; 166viii; 172; 179ix; 179xii; 179xiii; 190ii; 190iii; 197v; 198iii; 198iv; 202iii; 202iv; 203iii; 203vii; 207v; 207vii; 208iii; 218iii; 219ii; 222ii; 222iii; 223ii; 223iii; 226ii and 227iii). This denotes continuity in the text.

Like class (a) which indicates the prevalence of topical Themes in their usual position in the clause, classes (b) $(37.34 \%)$, (c) $(\mathbf{0 2 . 3 6 \%})$, (d) $(\mathbf{0 2 . 1 8 \%})$, (e) $(\mathbf{0 3 . 8 2 \%})$ and (f) $(\mathbf{0 1 . 2 7 \%})$ exhibit clauses in which topical Themes occur in their initial slot. While in class (b) these topical Themes are preceded by a conjunction encoding extension mainly, they are placed after a Mood element in (c). The huge number of class (b) (it ranks second with a rate of 205/549 (i.e., 37.34\%)) in this story denotes a considerable deployment of clause complexes therein. Two types of clause complexes are actually noted in this text: paratactic clause complexes and hypotactic clause complexes. But the rate of paratactic clause complexes, as the analysis exudes, strikingly outnumbers that of hypotactic clause complexes. This denotes a spoken mode in the story. Again, the analysis shows that, in the category of hypotactic clause complexes, there exist less marked dependent clauses $(26 \mathrm{i}, 28 \mathrm{i}, 33 \mathrm{i}, 62 \mathrm{i}, 70 \mathrm{i}, 86$, 92i, 94i, 97i, 113i, 117i, 122i, 130i, 145i, 149i, 175i, 177i, 180i, 181i, 183i, 185, 190i, 195i, 200 and 227i) than unmarked ones (82ii, 85iv, 93iv, 93v, 104ii, 107ii, 110ii, 110ix, 116ii, 117viii, 120ii, 125iii, 125iv, 127iii, 127vi, 133iii, 140iii, 141ii, 144ii, 149iii, 160ii, 161ii, 164iii, 165v, 166v, 166vi, 166x, 168ii, 168iii, 173ii, 186ii and 203ii). But the placement of the dependent clauses in Thematic position makes the text under study:

appear more spoken, as the frequent use of dependent clauses in Thematic position contributes to neutralizing the distinction between spoken and written language. Since clause complexes are more common in spoken language, while single clause sentences are frequent in written language, the presence of clause complexes suggests a spoken mode. However, by positioning the dependent clause[s] first, the writer gives the text a degree of Thematic planning not common in spoken language (Eggins, 2004:339).

Though used in relatively scanty rates in the story, classes (c) $(1 \mathrm{i}, 12,24,32,54,69,76,93 \mathrm{vi}, 134$, 147i, 165i, 203vi and 203vii) (13/549; 02.36\%), (d) (2i, 3, 27, 78ii, 79i, 87iv, 90i, 93vii, 93viii, 178, 188 and 202ix) (12/549; 02.18\%), (e) (11iii, 41i, 47iii, 52, 68, 77ii, 77iv, 77vi, 77vii, 82iv, 106iii, 110xii, 118vi, 120iv, 165ii, 166ix, 179xi, 179xii, 196ii, 202ii and 202iii) (21/549; 03.82\%), (f) (118v, 118vii, 165iii, 179xiii, 197iv, 197v and 202iv) (07/549; 01.27\%) and (g) (71, 72, 73 and 74) (04/549; 00.72\%) encode a spoken mode in the text too. For instance, the use of such Mood items as 'of course' in (1i, 12 and 165i), 'were' in (2i), 'hadn't' in (3), 'Is' in (24), 'So of course' in (27), 'Does' in (54 and 134), 'Maybe' in (69), 'Did' in (76), 'and perhaps' in (78iii), 'Oh, isn't' in (79i), 'and invariably' in (87iv), 'And would' in (90i), 'and could' in (93vii, 93viii and 203vii), 'Please don't' in (147i), 'And isn't' in (178), 'And of course' in (188) and 'So could' in (202ix and 203vi) attests to this. In the same way, the use of structural elements like 'which' in (47iii, 52, 67, 82iv, 110xii, 118vi and 120iv), 'who' in (77ii, 77iv, 77vi, 77viii, 106iii, 165ii, 202ii and 202iii), 'and which' in (118vii), 'in which' in (196ii) 'because ... who' in (197iv) and 'and who' in (197 and 202iv) indicates the writer's packaging of clause simplexes into clause complexes, which further unveils a spoken mode in the story.

\section{RECAPITULATION, INTERPRETATION OF THE FINDINGS AND CONCLUSION}

This study has set out to examine the Thematic structure and Thematic features in Ama Ata Aidoo's short story entitled "Comparison or Who Said a Bird Cannot Father a Crab?" in order to see how they realize the writer's literary style. It has revealed some very important findings tabulated below. 
Stylistic Study of Thematic Structure and Thematic Features in Ama A. Aidoo's "Comparisons or Who Said a Bird Cannot Father a Crab?"

Table3. Recapitulation of Major Findings in/from the short story.

\begin{tabular}{|l|l|l|}
\hline Feature & Number & Percentage (\%) \\
\hline Clause complexes & 227 & 100 \\
\hline Ranking clauses & 548 & 100 \\
\hline Major clauses & 544 & 99.27 \\
\hline Minor clauses & 04 & 00.72 \\
\hline Marked & 61 & 11.13 \\
\hline Dependent as Theme & 25 & 04.56 \\
\hline Structural element as Theme & 28 & 05.09 \\
\hline
\end{tabular}

As the table above shows, the story under study counts 227 clause complexes: 106 clause simplexes and 121 clause complexes. While the use of clause simplexes denotes a written mode, that of clause complexes indicates a spoken mode. The 227 clause complexes in turn incorporate a total number of 548 clauses. Out of these clauses, 544 (i.e. 99.27\%) represent major clauses. This exudes a written mode in the text. The presence of the $04(\mathbf{0 0 . 7 2 \%})$ minor clauses points to a spoken mode in the text. In addition, the use of marked Themes $(\mathbf{6 1 ; 1 1 . 1 3 \% )}$ suggests a careful rhetorical organization, which is typical of a rehearsed written text (Koussouhon and Allagbé, 2013). But the use of structural elements $(\mathbf{2 8} ; \mathbf{0 5 . 0 9 \%})$ indicates the packaging of clause simplexes into clause complexes, which is characteristic of a spoken language. The rate of dependent clauses $(25 ; \mathbf{0 4 . 5 6 \%})$ placed at/in Thematic position implies, as Eggins (2004:339) puts it, the neutralizing of the distinction between spoken and written language in the story.

In fact, this Theme analysis of Aidoo's short story has proved very challenging in that it (the text) is strikingly fraught with so many ellipsed clauses/clause complexes, fragments, null constituents /agent less/process less clauses/ clause complexes, capitalization, deferred referents/identities and especially the matized/ fore grounded features. It is also marked stylistically by a discontinued depiction/contrasted description (of past experience and recent experience, traditional life and modern life, boy education and girl education, masculine roles and feminine roles, fatherhood and motherhood, etc., in an African patriarchal setting). All these, as it were, denote a very complex literary style marked by a combination of the features of both spoken and written language. Finally, while this study has come up with considerably insightful results about Thematic structure which serves to realize Textual meaning in the short story under study, it has not explored both the Ideational and Interpersonal dimensions therein. Given that Theme analysis is affected by Taxis (Eggins, 2004), future research into this aspect could help gain an insight into the logico-semantic meaning of the story.

\section{REFERENCES}

[1] Aidoo, A. A. (2002). The Girl Who Can and Other Stories. Edinburgh Gate, Harlow, Essex, Cm20 2JE: Heinemann.

[2] Allagbé, A. A., \& Allagbé, M. A. (2017). "Systemic Functional Stylistic Appraisal of Chimamanda N. Adichie's Purple Hibiscus (2003)." In International Journal on Studies in English Language and Literature (IJSELL), 5(1), 69-86.

[3] Amoussou, Y. C. (2016). "Exploring the Textual Metafunction in a Biblical-Fictional Parable in Ngũgĩ wa Thiong'o's Devil on the Cross.” In International Journal of Applied Linguistics \& English Literature. Vol. 5 No. 5, 215-227.

[4] Bloor, T. \& Bloor, M. (2004). The Functional Analysis of English. London: Arnold.

[5] Eggins, S. (1994/2004). An introduction top systemic functional linguistics. London: Pinter.

[6] Fontaine, L. (2013). Analysing English Grammar: A Systemic Functional Introduction. New York: Cambridge University Press.

[7] Halliday, M. A. K. \& Matthiessen, C. M. I. M. (2004). An Introduction to Functional Grammar. London: Arnold.

[8] Halliday, M. A.K.\& Hasan, R. (1985). Language context and text: aspect of language in a social semiotic, perspective. Oxford: Oxford University Press.

[9] Halliday, M. A. K. and Hasan, R. (1976): Cohesion in English, London: Longman.

[10] Halliday, A. K. (1985). Linguistic Studies of Text and Discourse. New York: Continuum. 
[11] Halliday, A. K. (1985). An introduction to functional grammar. London, Melbourne, Auckland: Edward Arnold.

[12] Halliday, M. A. K. (1978). Language as Social Semiotic: The Social Interpretation of Language and Meaning. London: Edward Arnold.

[13] Halliday, M. A. K. (1976). An Introduction to Functional Grammar. London: Edward Arnold.

[14] Halliday, M. A. K. (1971). "Linguistic Function and Literary Style: An inquiry into the Language of William Goldingees The Inheritors". In S. B. Chatman (ed) Literary Style, London and New York: Oxford University Press.

[15] Koussouhon, A. L. and Allagbé, A. A. (2013). “The Lexicogrammar of Chimamanda Ngozi Adichie's Fiction: A Systemic Functional Contribution’. In Langage \& Devenir, N¹2, Revue Semestrielle. Pp. 1944.

[16] Leech, G. N. \& Short, M. H. (1981). Style in Fiction: A Linguistic Guide to English Fictional Prose. London: Longman.

\section{AUTHORS' BIOGRAPHY}

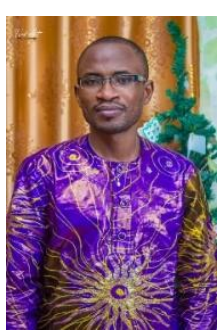

Ayodele Adebayo Allagbé got, a doctorate degree in Applied Linguistics from Université d'Abomey-Calavi, Republic of Benin, in 2015. He is a member of Laboratory for Research in Linguistics and Literature (LabReLL) and Groupe de Research sur l'Afrique et la Diaspora (GRAD). He is also the author and co-author of many papers published in prestigious local and international journals. His areas of interest include Systemic Functional Linguistics (SFL), Stylistics, Literary Criticism, Language and Teaching and Pragmatics.

Yémalo Célestin Amoussou, is a Senior Lecturer at the English Department as well as at Ecole Doctorale Pluridisciplinaire (EDP), Université d'Abomey, Republic of Benin. He is a member of Labora-tory for Research in Linguistics and Literature (LabReLL). He is also the author and coauthor of several articles pertaining to Systemic Functional Linguistics (SFL), mostly Discourse Analysis.

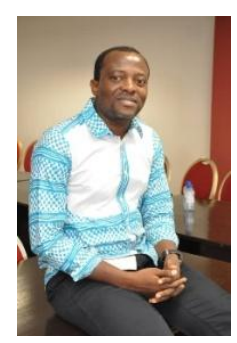

Dorothée Tchada, is a Doctoral Candidate in Applied Linguistics at Université d'Abomey, Republic of Benin. He is a co-author of a couple of articles related to Systemic Functional Linguistics, Stylistics, to name but a few. He is also the author of The Untamed Destiny, a novel. Besides, he is a member of the national board of the Benin National Teachers of English Association (BNTEA).

Citation: Ayodele Adebayo Allagbé, et.al., "Stylistic Study of Thematic Structure and Thematic Features in Ama A. Aidoo's "Comparisons or Who Said a Bird Cannot Father a Crab?"” International Journal on Studies in English Language and Literature (IJSELL), vol 8, no. 9, 2020, pp. 1-12. doi: https://doi.org/10.20431/23473134.0809001.

Copyright: (1) 2020 Authors. This is an open-access article distributed under the terms of the Creative Commons Attribution License, which permits unrestricted use, distribution, and reproduction in any medium, provided the original author and source are credited. 